\title{
Information Security and Blended Learning System Environment (BLSE)
}

\author{
Walid Qassim Qwaider \\ Majmaah University \\ College of Science and Humanities in Ghat \\ Management Information Systems Department, Saudi Arabia
}

\begin{abstract}
In the past few years have witnessed a quantum environment, the quality of education as a result of the rapid growth in technology. Blended Learning System (BLS) is a new way of learning, which ultimately depend on the (traditional learning or online) in its implementation. Internet has become a place for a new set of illegal activities, and is now under the blended learning system environment (BLSE) to such challenges. In this paper, is to put all $B L S$ context, definition, characteristics and benefits and the challenges it. This paper discusses the information security elements required to be implemented within the BLSE, however, the paper, and define information security countermeasures that can enhance the security of information within the BLSE.
\end{abstract}

\section{Introduction}

Information security (IS) has become essential to many, if not all information technology systems particularly important for systems to use the Internet as a means of delivery. And well aware of this fact and expressed appreciation for good in the financial systems - systems specifically for education on the Internet. With the increasing demand for IS professionals, and many organizations to create information security program [1].

The main reason why IS very important within the BLSE is that the main feature that distinguishes between the BLS including e-learning and face-toface interaction environments is the degree of use of technology and the gradual shift of control and responsibility in the learning process for learners, giving them the opportunity to learn anytime, anywhere use the BLS, however, can lead to many of the potential risks to the security of information that could harm the information [2]. These risks are not necessarily unique to BLSE but should nevertheless be treated as if they had anywhere. It is therefore important that is to take all necessary steps from the educational institutions to ensure secure information correctly within BLSE [3].
The first part of this paper discusses the context of the BLS, the definition, features, and benefits and all the challenges which are considered safe in the BLS as a new challenge in the implementation of BLSE. Moreover, applications of the Internet are the medium used to help the vast majority of online services, and thus became a prime target for cyber attacks.

The second Part of this paper looks at information security in BLSE neglected in research. Issues such as legitimate users, and of course the reliability of the content, and accessibility (including the admissibility and availability), as well as other considerations, all of which need to be addressed carefully in order to ensure the learning process can take place effectively. Finally, the paper will discuss the potential elements of the security information required to be implemented within the environment BLS, however, the paper, and define information security countermeasures that can enhance the information security within the BLSE.

\section{Blended Learning System (BLS)}

Blended learning systems means many things to many people, even within our relatively small community of online learning. And referred to as both blended and hybrid learning, with a slight difference or not in the meaning of terms among most teachers. In general terms, blended learning that combines online delivery of educational content with the best features of classroom interaction and education to direct the allocation of education, and allow thoughtful reflection, and differentiate instruction from student to student across a variety of learners.

Definitions of a wide range of blended learning system, so that some of the practical, any learning experience that integrates some of the educational use of technology to qualify, to others that focus on the combination of a certain percentage of the curriculum via the Internet and education in the development and face to face [7].There are a few of the many definitions of blended learning system include the following, Figure 2 below: 


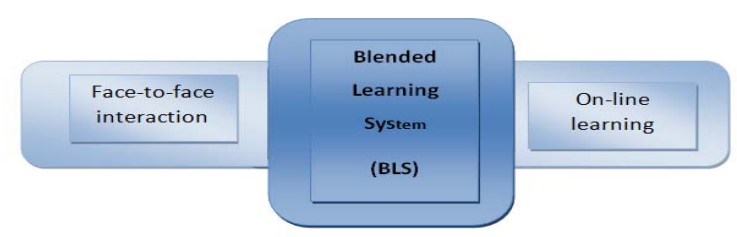

Figure 2. Defining the BLs

- integration of face-to-face online to help promote the experience of the classroom and extend learning through the innovative use of information technology and communications. Strategies to promote the participation of blended students, and learning through online activities in the curriculum, and improve the effectiveness and efficiency by reducing time lecture [8].

- "A course that blends delivery of online and face to face. Be delivered a large percentage of online content, and is commonly used online discussions, and usually have some meetings and face to face." Group Sloan knows sessions blended as between 30 percent and 79 percent of content delivered online, with the remaining part of the course content delivered by face-to-face instruction or other organizations on the Internet and media, such as textbooks and paper [9].

Blended learning system should be viewed as a pedagogical approach that combines educational opportunities and the effectiveness of the socialization of the classroom with the possibilities of technologically enhanced learning environment for the active on the Internet, rather than the rate of delivery methods [7].

\subsection{BLS Benefits}

There are many benefits of using blended learning system are:

1. Improve learning: In 2002, the validation IDC Knowledge Nets ability to deliver measurable results and effective blended learning. Independent research study of nearly 4000 of the educated and revealed 35 percentage points after the completion of training learners knowledge networks [10]. He said most companies that BLS programs built solve the problems that were impossible to solve in any other way [11].

2. The best of both worlds: the goal and take advantage of blended learning using various learning styles in order to get the best of all worlds. BLS developed as an attempt to gain the benefits of BLS while using other means to overcome the problems. 3. Efficiency: BLS can provide a reduction of costs, time and work, stress, etc. and is usually achieved by using computers. Maintain a line of materials easier to access, distribute, and reproduce. Can access the materials on the spot many of the sites at any time?
4. Cooperative learning: A common feature in mixed lessons is that students work in pairs or groups to complete the task. Education is not just a transfer of information, but also on skills development and social interaction [10].

5. Preparation for action: BLS is a good preparation for work, be the cause in a way that is similar and thus mimic, conditions of employment and experience. In the lessons and blended and employment, and tend to be joint ventures related, are not isolated, and tasks.

\section{Blended Learning System Environmernt (BLSE)}

BLSE there are different opinions about the impact of technology in education. One of the first arguments questioning the role of technology in learning comes from. Argues that technology is not only a means that will provide education, and technology that will not affect student learning. He explained in the way of instruction is the most important consideration for this purpose [12].

BLS is part of the ongoing convergence of the two biblical learning environments. On the one hand, we have the learning environment of traditional faceto-face that has been around for several centuries. On the other hand, we distributed learning environments, which began in the growth and expansion in exponential ways and new technologies have expanded the possibilities of communication and interaction and distributed [13].

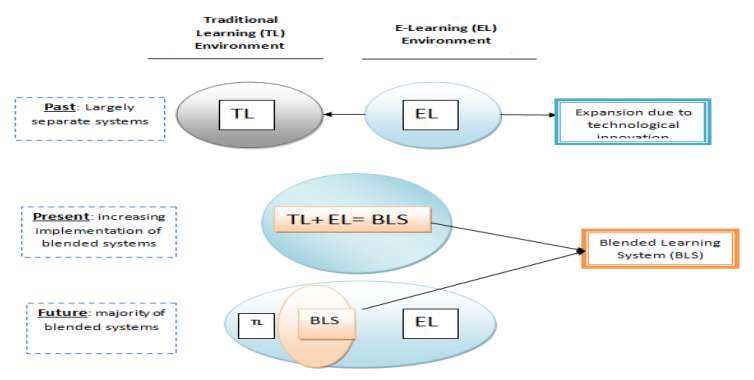

Figure 3. BLS Environment

In the past, these were still two separate learning environments to a large extent because they used different media, and combinations, style and meet the needs of different audiences (see Figure 3). For example, the traditional face-to-face learning and usually occurred in the environment under the guidance of a teacher with a live person to person interaction in the synchronous environment, a high accuracy. On the other hand, said after learning systems for self-learning, learning materials, the interactions that occurred in the normally asynchronous, low-resolution (text only) environment. 


\section{Challenges in the BLS}

There is a saying in the world of BLS. This is true when it comes to BLS as well. Can be sure that participants have a need for hardware, software and bandwidth cannot be ignored in the implementation of co-education system. Can not the level of technical skills of learners and facilitators also a major challenge for BLS. Provide technical support and adequate training to the participants and facilitators is vital to the success of BLS.

May include the BLS approach also entails a cultural shift on the part of both participants and their managers. Educated people are more aware of people in training, and managers may be more accustomed to send employees to training outside the site where the clearly carved out of time and place for learning. The successful implementation of co-education system requires the active support and encouragement from managers and supervisors in all parts of the project.

For effective learning online, learners need to be calm, and a space dedicated to computer staff to participate without interruption. It is often difficult to find this space and take time to learn on the Internet while setting aside the demands of daily work in the library. BLS places more responsibility for learning in the hands of the learner, and for some learners are not used to independent learning, and this can be a challenge. Building support for learners of trainers, supervisors and colleagues helps to increase completion rates and course satisfaction of the learner.

BLS also requires a deliberate approach to instructional design so that it is blending in the program design, not only in delivery. Professional development for teachers to learn strategies for online teaching and facilitation skills important to any successful program blended. It must also be trained to know all of the technologies that will be used and blended in the program and be able to support learners. Finally, we must also learn to integrate the trained methods of assessing student learning in the context of BLS [14].

\section{Informatio Security (IS)}

The information consists of bits of data: ones and zeros. You can create a duplicate copy of the information with little or no trace of this activity. Similarly, it can easily be modified by changing the information on these bits of data. Due to the nature of the information, and there is no way to ensure safety and full security [3]. Instead, information security should be an attempt to achieve balance and risk control, and represent a sort of balance. It is very difficult to know exactly what are the controls necessary to ensure the minimum security of information within the information system. Figure 4 shows that there is a general view, security is the quality or state of being safe, to be free of risk [15]. It consists of three basic elements of security: assets, vulnerabilities and threats each of which is examined in more detail [17].

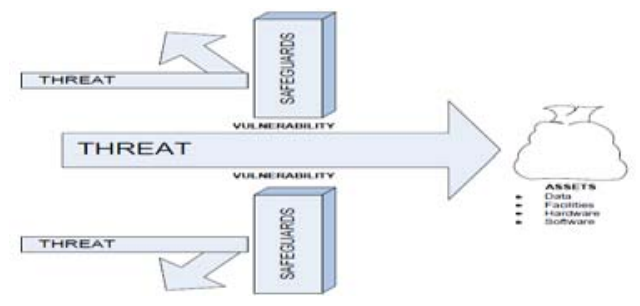

Figure 4. Elements of Security [16]

\section{Information Security for the Implementation of BLS}

It is essential that all institutions that guarantee not only for the BLS information security a properly designed but also implemented correctly. BLS and information security policy of no value if it is stored somewhere on the shelf and is not used to secure information. If BLS is executed for the security of information within the institution, it's just as bad as not having one at all. Otherwise, the implementation of BLS to the security of information, but ultimately the responsibility of senior management.

Countermeasures: With the increasing IS threats within BLSE as shown above, institutions should implement technical, as well as countermeasures for the information security to ensure the availability, integrity and confidentiality of their information[3]. Will implement these countermeasures help ensure appropriate protection for teachers and students, as well as data against possible security incidents. These countermeasures for the information security is [1]:

1. Identification and authentication: Make sure that the user is who he / she, and claims that, to ensure that access granted to the user. The first part of this service is to determine whether or not the person who is trying to clear the access to the system to gain access. This is called the identification process, and is usually done by entering the user in the system. Once one has been identified, the user, and system must ensure that the user is really who he / she claims. This is called the authentication process. It can be done through the user authentication knows something, such as passwords, the user has everything, like getting a card or something from the user, such as fingerprints [18]. Counter-examples to the security of information for identification and authentication include passwords and login IDs, unique sound. 
2. Authorization: to ensure that the user has the authority to access the system or information. This involves determining whether or not a party to authenticate the right of access to the information in question [18]. An example of countermeasures for the security of information to get authorization is access control.

3. Confidentiality: to ensure that the information not be disclosed to any unauthorized person. The purpose of confidentiality is to ensure that the information and data did not reveal to any person or entity is authorized. Example of confidential information to the security of anti-encryption.

4. Safety: to ensure that the information has not changed in its original form and there is no manipulation or change has taken place. In other words, may not be the entities entitled to change the content of information, unauthorized modification must be prevented. Counter-example that will help to ensure the integrity and message authentication codes.

5. Non-repudiation: ensuring that the person cannot take actions that could be denied later. This service guarantee to take any action that affects the security of the information can be denied at a later stage [18]. An example of information security countermeasure for non-repudiation of digital signatures.

6. Availability: ensuring that information is available at any given time, which means that the data and information can be accessed at any time to the concerned authority. An example of countermeasures to information security and availability of the backup regulator.

Can be coded with information from an external source: but, if they lack the ability to decrypt this information, although it has been breached attribute possession of confidential information and did not do so, Figure 5 shows Implementation Information Security for BLS.

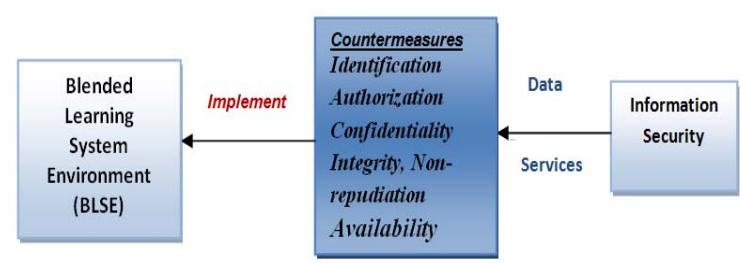

Figure 5. Implementation Information Security for BLS

These countermeasures are in the first place, the information security and information security technology because of their anti-art (for example, encryption, access control lists and message authentication codes). However, information security is not just a technical issue but a business issue as well. The next subsection achieves various commercial or procedural information security countermeasures.

\section{Conclusion}

BLS (traditional learning or online), which itself contributes to the many threats to information security. It is therefore important that BLSE should ensure a proper understanding of information security countermeasures and implement the best possible way. And benefits offered by the increasing number of users BLS. BLSE ensure the availability and integrity of the information and materials within BLSE requires countermeasures, and flexibility offered by the BLS and behaviours a different user, BLS requires a framework for security management, which can serve as a guide to help the provider BLS (institutions) in the management of information security within the BLSE. Moreover, the set of the International Solidarity Movement and the security of current information technology used to provide better results in the successful implementation of the security.

\section{References}

[1] Kritzinger E., Solms S.H., E-learning: Incorporating Information Security Governance, Issues in Informing Science and Information Technology Volume 3, 2006.

[2] Tselios, N., Daskalakis, S., \& Papadopoulou, M. Assessing the Acceptance of a Blended Learning University Course. Educational Technology \& Society, 14 (2), 224-235, 2011.

[3] Kritzinger E., Information Security in an E-learning Environment, School of Computing, University of South Africa, PO Box 392, UNISA, 003, South Africa, 2006.

[4] Singh. H, Building Effective Blended Learning Programs, Educational Technology, 43(6), 51-54, 2003.

[5] Banadosa, E., Blended-learning Pedagogical Model for Teaching and Learning EFL Successfully Through an Online Interactive Multimedia Environment, CALICO Journal, Vol. 23, No. 3, p-p 533-550, 2006.

[6] Aytac. T, "The influence of blending model on developing Leadership Skills of School Administrator" conference, - Applied Computing, special Issue on ICIT 2009.

[7] Watson, John Blending Learning: The Convergence of Online and F 3 ace-to-Face Education, North Amarican Council for Online Learning, February 8, 2008.

[8] University of Calgary, Teaching and Learning Centre, retrieved March 3, 2008. from http://commons.ucalgary.ca/ teaching/programs/itbl/

[9] Blending In: The Extent and Promise of Blended Education in the United States, Allen, Seaman and Garrett, March, 2007. 
[10] Jared M. Carman. Blended Learning Design: Five key Ingredients, He holdsan MS in Instructional Technology from Utah State University, October, 2002.http://www.agilantlearning.com/pdf/Blended\%20Lea rning\%20Design.pdf.

[11] Bersin Josh and Associates. Blended learning: What works?, Retrieved 17 August, 2006, from http://www.elearningguru.com/wpapers/blended_bersin.do c.

[12] Clark R. E., Media and method, Educational Technology Research \& Development, 42(3), 7-10, 1994.

[13] Alexakos C. E., Giotopoulos K. C., Beligiannis G. N., Likothanassis S. D. Integrating E-learning Environments with Computational Intelligence Assessment Agents Integrating Agents and Computational Intelligence Techniques in E-learning Environments, word Academy of Science, Engineering and Technology, 2005.

[14] Staley. L., Blended Learning Guide, Spanish Language Outreach Program Coordinator, Web Junction, March 2007.

[15] Whitman, E., \& Mattord, H. (2003). Principles of information security. Thomson Course Technology.

[16] Goss R. Gavin., Enabling e-Learning 2.0 in InformationSecurity Education: A Semantic WebApproach, Nelson Mandela Metropolitan University, January 2009.

[17] Goguen, A., Stoneburner, G., \& Feringa, F. (2002). Risk management guide for information technology systems. NIST Special Publication 800-30.

[18] Solms V., S. H. \& Eloff, J. H. P., (2004). Information security, Johannesburg, South-Africa.

[19] Adams. J., Blenkharn A., Briggs. G. et al.,"Report to the Learning, Teaching and Assessment Committee of the Blended Learning Task and Finish Group Faculty of Health and Human Sciences, March, 2006. 